GABA-GABA: Jurnal Pengabdian Masyarakat dalam bidang Pendidikan Bahasa dan Seni Vol. 1 No. 2, November 2021, Hal 74-81

e-ISSN : 2797-8494

\title{
MODEL PEMBIMBINGAN TUTOR SEBAYA MELALUI MODIFIKASI PERLAKU KOGNITIF
}

\author{
Marshallo R. Kakerissa ${ }^{1}$,Jolanda Tomasouw ${ }^{2}$, Juliaans E.R.Marantika ${ }^{3}$ \\ ${ }^{1,2,3}$ Faculty of Teacher Training and Education, Universitas Pattimura, Indonesia \\ *Corresponding e-mail: marland_mt@yahoo.co.id
}

\begin{abstract}
Abstrak
Pendampingan dalam proses belajar mengajar merupakan salah satu indikator penting yang dapat menunjang hasil belajar. Berbicara tentang pendampingan atau pembimbingan bagi tutor sebaya memerlukan pendekatan tersendiri. Keberadaan siswa saat ini sangat tidak stabil dalam arti mereka masih mencari jati diri mereka dan hal itu sangat berpengaruh baik dalam proses belajar mengajar maupun hasil belajar. Dalam pengajaran bahasa asing yakni bahasa Jerman yang diajarkan di sekolah- sekolah merupakan bahasa asing kedua selain bahasa Inggris banyak hal yang ditemui di lapangan. Penguasaan bahasa Jerman siswa masih jauh dari apa yang diharapkan, hanya sebagian siswa yang memiliki kemampaun di atas rata-rata. Hal tersebut disebabkan karena sifat para siswa SMA masih tergolong dalam masa transisi. Pemahaman terhadap remaja akan semakin jelas bila diketahui bahwa adanya kelompok-kelompok yang terdiri dari jenis kelamin yang berbeda baik sekelompok sahabat (cliques), sahabat karib (chums) maupun kelompok gangs (crowds). Oleh karena sekolah dan keluarga akan selalu berhadapan dengan kelompok sebaya. Untuk mengatasi masalahmasalah yang dapat ditimbulkan dari kelompok tutor sebaya yang menjurus pada hal-hal negatif maka selaku pendidik akan berusaha dengan berbagai cara untuk membina para remaja dengan melakukan pembimbingan melalui teknik modifikasi perlaku kognitif. Modifikasi perilaku kognitif adalah teknik menggabungkan terapi kognitif dan bentuk modifikasi perilaku individu yang bertindak dalam usaha membangun perilaku adaptif melalui pelajaran keterampilan-keterampilan yang terdapat pada terapi perlakuan khususnya pada mata pelajaran Bahasa Jerman dengan tujuan untuk mengubah sikap dan perilaku siswa untuk menerima pelajaran dengan baik yang dituntun dalam suatu pendampingan oleh teman sebaya. Dengan demikian diharapkan melalui pengembangan model pembimbingan teman sebaya ini hasil belajar siswa dapat ditingkatkan dan pengajar juga memiliki panduan atau pedoman yang jelas untuk mengarahkan siswa untuk meningkatkan prestasi mereka.
\end{abstract}

Kata Kunci : Modifikasi Perilaku Kognitif, Tutor Sebaya

\begin{abstract}
Mentoring in the teaching and learning process is one of the essential indicators that can support learning outcome. Mentoring for peer tutors requires a different approach. The existence of students today is precarious because they are still looking for their identity, and it is very influential in both the teaching and learning process and learning outcomes. Understanding of adolescents will be more apparent if it is known that groups consist of different genders, both groups of friends (cliques), best friends (chums), and groups of gangs (crowds). Because of that, schools and families will always be faced with peer groups. Cognitive behavior modification is a technique of combining cognitive therapy and a form of individual behavior modification. The aim of this study is to change students' attitudes
\end{abstract}


and behavior to receive lessons well that are guided in peer assistance. The respondents were students of SMAN 1 and SMAN 7 Ambon, a total of 50 people. The method used is descriptive. Data collection techniques using observation and questionnaires. Thus, we are hoping that through the development of this peer mentoring model, student learning outcomes can be improved, and teachers also have clear guidelines to direct students to enhance their achievements.

Keywords: Cognitive Behavior Modification, Peer Tutor

\section{PENGANTAR}

Modifikasi perilaku-kognitif merupakan teknik menggabungkan terapi kognitif dan bentuk modifikasi perilaku. Individu yang bertindak, sebelumnya didahului adanya proses berpikir, sehingga bila ingin menggubah suatu perilaku yang tidak adaptif, terlebih dahulu harus memahami aspek -aspek yang berada dalam pengalaman kognitif dan usaha untuk membangun perilaku adaptif melalui mempelajari keterampilan-keterampilan yang terdapat pada terapi perlakuan. Namun dibalik tingkah laku yang tampak terdapat proses internal yang sebenarnya merupakan hasil pemikiran kognisi. Oleh sebab itu dalam modifikasi perilaku-kognitif terdapat berbagai macam prosedur, termasuk di dalamnya misalnya terapi kognitif, terapi emotif rasional, latihan penurunan stress, latihan pengelolaan kecemasan, kontrol diri, dan latihan instruksi diri. kemampuan berbicara adalah mampu mengorganisasikan ide- ide yang dikemukakan oleh lawan bicaranya serta mampu mengorganisasikan ide-ide yang akan diungkapkan. Oleh karena itu, untuk mencapai kemampuan tersebut maka kemampuan berbicara perlu dilatih dan dipelajari baik melalui lingkungan keluarga, sekolah maupun masyarakat kemampuan berbicara adalah

mampu mengorganisasikan ide- ide yang dikemukakan oleh lawan bicaranya serta mampu mengorganisasikan ide-ide yang akan diungkapkan.

\section{Hakikat Tutor Sebaya}

Tutor sebaya merupakan sekelompok siswa yang telah tuntas terhadap bahan pelajaran, dan dianggap mampu memberikan bantuan kepada siswa yang mengalami kesulitan dalam memahami bahan pelajaran yang dipelajarinya. Seorang atau beberapa orang siswa yang ditunjuk oleh guru, untuk membantu guru dalam melakukan bimbingan terhadap kawan sekelas. Dengan sistem pembelajaran menggunakan tutor sebaya, akan membantu siswa yang belum mencapai nilai Kriteria Ketuntasan Minimal (KKM), atau kurang cepat menerima pelajaran dari guru (Herianto dkk, 2010:2).

Dewi (2020, p. 169) mengemukakan bahwa untuk membangun pembelajaran yang 
menyenangkan bagi siswa maka guru diharapkan memiliki kompetensi guna meningkatkan mutu peserta didik. Peserta didik dianggap memiliki mutu yang berkualitas apabila dalam proses pendidikan dapat tercipta suatu kondisi yang kreatif, aktif, menyenangkan, dan untuk outputnya memiliki keterampilan sesuai dengan bidangnya. Menurut Luarmasse et al., (2021, p. 48), Kognitif siswa akan terbangun melalui proses daya ingat, dan hal tersebut dapat dilatih dengan menggunakan media pembelajaran sebagai alternative disamping itu juga dapat melatih ingatan siswa melalui pendengaran dan penglihatan maka besar kemungkinan siswa dapat mengingat materi ajar yang diberikan oleh guru dalam jangka Panjang. Sedangkan Tutor berfungsi sebagai pelaksana mengajar yang cara mengajarnya telah disiapkan secara khusus dan terperinci. Untuk menimbulkan susasana kompetitif, setiap kelompok harus terus dipacu untuk menjadi kelompok yang terbaik. Peran tutor sangat besar pengaruhnya terhadap keberhasilan kelompok dalam mempelajari materi ajar yang disajikan melalui metode diskusi kelompok tutor sebaya (Herianto dkk, 2010:2-3). Menurut Surya (dikutip dari Soeprodjo dkk, 2008, p. 295), metode tutor sebaya merupakan metode yang dilakukan dengan cara memperdayakan kemampuan siswa yang memiliki daya serap tinggi, siswa tersebut mengajarkan materi atau latihan kepada temantemannya yang belum paham.

Ini berarti bahwa tutor adalah murid yang tergolong baik dalam prestasi. Ada beberapa keuntungan metode tutor sebaya antara lain, 1) adanya suasana hubungan lebih akrab antara murid dengan tutor, 2) bersifat efisien, 3) bagi tutor merupakan pengayaan dan, (4) dapat meningkatkan rasa tanggung jawab. Namun demikian ada kekurangannya yaitu guru harus tahu siswa yang mempunyai pemahaman lebih, pengawasan tutor harus dilakukan dengan baik dan proses tutoring akan terhambat manakala siswa yang ditutori merasa rendah diri. Permasalahan dalam metode ini antara lain apabila di dalam kelas tidak ada yang mampu dan bersedia menjadi tutor sebaya.

Menurut Utari et al., (2021, p. 20), kriteria untuk menjadi tutor dalam model pembelajaran peer tutoring terdapat beberapa persamaan kriteria untuk menjadi seorang tutor yaitu berprestasi baik, memiliki prestasi dan kepandaian yang lebih unggul dibandingkan peserta didik lainnya, dapat diterima dan disetujui oleh semua anggota kelompoknya, sehingga anggota didalam kelompoknya tidak akan canggung untuk bertanya kepada tutor tersebut sehingga akan meningkatkan hasil belajar, karena apabila peserta didik memiliki kesulitas dalam mengerjakan tugas atau ada materi yang belum peserta didik pahami maka peserta didik dapat bertanya dan 
meminta bantuan kepada tutor tanpa adanya rasa takut untuk bertanya. Seorang tutor hendaknya memiliki kriteria yaitu, memiliki kemampuan akademik di atas Tutor atau ketua kelompok memiliki tugas dan tanggung jawab sebagai berikut yaitu, 1) memberikan tutorial kepada anggota terhadap materi ajar yang dipelajari, 2) mengkoordinir proses diskusi agar berlangsung kreatif dan dinamis, 3) menyampaikan permasalahan kepada guru pembimbing apabila ada materi ajar yang belum dikuasai, 4) menyusun jadwal diskusi bersama anggota kelompok, baik pada saat tatap muka di kelas maupun di luar kelas, secara rutin dalam memecahkan masalah yang dihadapi, 5) melaporkan perkembangan akademis kelompoknya kepada guru pembimbing pada setiap materi yang dipelajari, peran guru dalam metode diskusi kelompok terbimbing dengan tutor sebaya ketika betul-betul diperlukan oleh siswa (Setiawati, 2009:11).

\section{METODE PENGABDIAN}

Dalam rangka melakukan pengabdian pada masyarakat maka metode yang digunakan adalah metode kualitatif, dimana penulis melakukan survey ke sekolah-sekolah sasaran untuk mengetahui metode dan strategi pembelajaran yang digunakan oleh guru, sehingga hasil yang diperoleh benar-benar representatif. Yang menjadi responden adalah siswa pada SMAN 1 dan siswa SMAN 7 Ambon dengan jumlah sampel 50 siswa. Kegiatan Pengabdian ini dilakukan pada Tahun ajaran 2020/2021. Teknik pengumpulan data adalah kuisioner. Data diolah dengan menggunakan skala likert

\section{HASIL DAN PEMBAHASAN}

Pengabdian ini bertujuan untuk melihat sejauh mana peranan tutor sebaya dalam proses pembelajaran. Oleh karena dipilih beberapa orang siswa untuk menjadi tutor bagi temannya. Tentu saja mereka harus memenuhi kriteria tertentu sehingga mereka mampu memerankan perannya sebagai tutur yang baik. Berdasarkan hasil yang ditemui dilapangan maka dihasilkan model pembimbingan tutor sebaya melalui modifikasi perilaku kognitif. Diharapkan model yang dihasilkan dapat digunakan di sekolah-sekolah.

Tabel 1 Tugas Guru dalam Model Pembimbingan Tutor sebaya

Melalui Modifikasi Perilaku kognitif 


\begin{tabular}{|c|l|}
\hline \multicolumn{1}{|c|}{ Tahap } & \multicolumn{1}{|c|}{ Aktivitas Guru } \\
\hline \multirow{2}{*}{$\begin{array}{c}\text { Menyeleksi siswa } \\
\text { calon tutor }\end{array}$} & $\begin{array}{l}\text { Menentukan siswa yang mampu menjadi tutor dalam kelas } \\
\text { dengan melihat berbagai aspek antar lain: memiliki prestasi yang } \\
\text { baik: mampu berintegrasi, kooperatif; memiliki jiwa } \\
\text { kepemimpinan dan bertanggungjawab. }\end{array}$ \\
\hline Menjelaskan & $\begin{array}{l}\text { Menjelaskan maksud kegiatan tutorial. Selain membantu teman } \\
\text { sekelas dalam memahami materi pelajaran, siswa juga dilatih } \\
\text { untuk bekerja sama, jujur dan terbuka sehingga melalui tutor } \\
\text { sebaya karakter sesama mereka dapat terbentuk.. }\end{array}$ \\
\hline Perencanaan & $\begin{array}{l}\text { Guru mempelajari bahan ajar dengan seksama dan } \\
\text { mengidentifikasi bagian-bagian yang sulit dari isi bahan ajar } \\
\text { kemudian menyusun strategi untuk membantu siswa } \\
\text { menghadapi kesulitan agar bisa mempelajari bagiannya yang } \\
\text { sulit. }\end{array}$ \\
\hline Pelaksanaan & $\begin{array}{l}\text { Guru mengidentifikasi siswa yang menghadapi kesulitan dalam } \\
\text { memahami bahan ajar yang diberikan dan sulit dipahami dan } \\
\text { melaksanakan tutorial dengan menggunakan bahan dan } \\
\text { langkah-langkah yang telah disiapkan. }\end{array}$ \\
\hline Mengevaluasi & $\begin{array}{l}\text { Melakukan tanya jawab untuk meyakinkan bahwa siswa } \\
\text { tersebut telah mengatasi kesulitan belajarnya dan memahami } \\
\text { materi yang sedang dipelajari dan memberikan tugas mandiri. }\end{array}$ \\
\hline
\end{tabular}

Tabel 2. Peran Siswa dalam Model Pembimbingan Tutor Sebaya

\begin{tabular}{|c|l|}
\hline Indikator & \multicolumn{1}{|c|}{ Kegiatan Tutor } \\
\hline \multirow{3}{*}{ Memberikan Arahan } & $\begin{array}{l}\text { Memberikan arahan kepada kelompok atau teman tentang proses } \\
\text { pembimbingan sehingga memiliki persepsi yang sama. } \\
\text { Menentukan teknik pendampingan seperti apa yang kelompok } \\
\text { kehendaki }\end{array}$ \\
\hline Pelaksanaan & $\begin{array}{l}\text { Kelompok dibagi berdasarkan jumlah anggota. Minimal 3 orang } \\
\text { satu kelompok. }\end{array}$ \\
\hline
\end{tabular}




\begin{tabular}{|c|c|}
\hline $\begin{array}{c}\text { Pelaksanaan/ } \\
\text { Pemahaman Materi }\end{array}$ & $\begin{array}{l}\text { Berinteraksi dengan siswa untuk menemukan ide-ide mereka. } \\
\text { Bertanya untuk mengetahui alasan mereka sebagai bahan } \\
\text { refleksi. Membantu mereka memahami materi yang dianggap } \\
\text { sulit dengan cara berdiskusi, sharing, mencari solusi dari suatu } \\
\text { permasalahan. }\end{array}$ \\
\hline Penerapan & $\begin{array}{l}\text { Kemempelajari bahan ajar dengan seksama dan } \\
\text { mengidentifikasi bagian-bagian yang sulit dari isi bahan ajar } \\
\text { kemudian menyusun strategi untuk membantu siswa } \\
\text { menghadapi kesulitan agar bisa mempelajari bagiannya yang } \\
\text { sulit. }\end{array}$ \\
\hline Pengidentifikasian & $\begin{array}{l}\text { mengidentifikasi siswa yang menghadapi kesulitan dalam } \\
\text { memahami bahan ajar yang diberikan dan sulit dipahami dan } \\
\text { melaksanakan tutorial dengan menggunakan bahan dan } \\
\text { langkah-langkah yang telah disiapkan. }\end{array}$ \\
\hline Evaluasi & $\begin{array}{l}\text { Melakukan tanya jawab untuk meyakinkan bahwa siswa } \\
\text { tersebut telah mengatasi kesulitan belajarnya dan memahami } \\
\text { materi yang sedang dipelajari dan memberikan tugas mandiri. }\end{array}$ \\
\hline
\end{tabular}

Menurut Ginting (dikutip dalam Amizatul dan Rusijono, 2010, p.30), penjelasan mengenai tahapan- tahapan kegiatan pembelajaran dengan menggunakan pembelajaran tutor sebaya. Tahapan- tahapan tersebut adalah sebagai berikut :

1) Langkah perencanaan, guru mempelajari bahan ajar dengan seksama dan mengidentifikasi bagian-bagian yang sulit dari isi bahan ajar kemudian menyusun strategi untuk membantu siswa menghadapi kesulitan agar bisa mempelajari bagiannya yang sulit.

2) Langkah persiapan, guru menyiapkan bahan ajar tambahan seperti variasi, contohcontoh penyelesaian soal atau LKS.

3) Langkah pelaksanaan, guru mengidentifikasi siswa yang menghadapi kesulitan dalam memahami bahan ajar yang diberikan dan sulit dipahami dan melaksanakan tutorial dengan menggunakan bahan dan langkah-langkah yang telah disiapkan.

4) Langkah evaluasi, guru melakukan tanya jawab untuk meyakinkan bahwa siswa 
tersebut telah mengatasi kesulitan belajarnya dan memahami materi yang sedang dipelajari dan memberikan tugas mandiri.

Salah satu sifat utama dari hubungan yang bersifat primer dari peran tutor sebaya adalah adanya kesamaan tujuan dan individu yang tergabung dalam kelompok. Hubungan-hubungan ini bersifat pribadi, spontan, sentimental dan inklusif. Persamaan tujuan ini mempunyai dua arti yaitu (1) individu yang bersangkutan mempunyai keinginan dan sikap yang sama pula, (2) satu pihak ada yang bersedia untuk berkorban demi kepentingan pihak lain. Itu berarti adanya nilai sosial, sebab dalam saling hubungan ini bersifat suka rela, semua pihak benar-benar merasakan suatu kebebasan dalam pelaksanaan. Sifat hubungan bersifat pribadi. Hal ini berarti bahwa saling hubungan dalam kelompok itu terjalin bukan karena diberi sesuatu yang bersifat material. Hubungan antar pribadi tidak dapat digantikan dengan orang lain. Suatu kelompok belajar yang terdiri dan lima orang, kelompok ini tidak dimasuki oleh anak lain biarpun dapat menurunkan biaya yang ditanggung kelompok ini. Oleh karena itu kelompok utama juga bersifat inklusif.

Beberapa penelitian yang sudah membuktikan bahwa pembelajaran dengan peer tutoring efektif untuk meningkatkan hasil belajar siswa (Laksemiwati, 2019). Disamping itu juga Salamony et al (2021, p. 24) menambahkan bahwa keberhasilan ataupun tidak tercapaianya tujuan pembelajaran tergantung kepada bagaimana proses pembelajaran yang dialami oleh siswa dalam rangka upaya mendapatkan hasil belajar yang baik.

\section{KESIMPULAN DAN SARAN}

Kegiatan belajar mengajar, anak adalah sebagai subjek dan sebagai objek dari kegiatan pengajaran. Karena itu, inti proses pengajaran adalah kegiatan belajar anak didik dalam mencapai suatu tujuan pengajaran. Tujuan pengajaran tentu saja akan tercapai jika anak didik berusaha secara aktif untuk mencapainya. Keaktifan anak didik di sini tidak hanya dituntut dari segi fisik, tetapi juga dari segi kejiwaan (Ahdiyat, 2015, p. 5). Dengan demikian untuk mencapai hasil yang maksimal maka metode tutor sebaya sangat efektif digunakan dalam kelas maupun sekolah. Karena melalui anak akan diberikan pendampingan oleh temannya sendir yang tentu saja telah memenuhi berbagai kriteria. Pengabdian yang dilakukan ini menghasilkan sebuah panduan model pembimbingan tutor sebaya yang dapat digunakan. 


\section{REFERENSI}

Ahdiyat, M. (2015). Metode Tutor Sebaya Untuk Meningkatkan Hasil Belajar Matematika Pada Materi Pengolahan Data. Faktor: Jurnal Ilmiah Kependidikan, 1(2).

Dewi, P. (2020). Penerapan Peer Tutoring Dilengkapi Handout Untuk Meningkatkan Motivasi Dan Hasil Belajar Siswa. Jurnal Pelita Pendidikan, 8(3).

Laksemiwati, N. L. A. (2019). Implementasi Model Pembelajaran Tutor Sebaya (Peer Tutoring) untuk Meningkatkan Aktivitas dan Hasil Belajar Tata Hidang. Journal of Education Action Research, 3(1), 31-37. https://doi.org/https://doi.org/10.23887

Luarmasse, N., Serpara, H., \& Marantika, J. (2021). Pengaruh Media Pembelajaran Permainan Monopoli Terhadap Keterampilan Berbicara Siswa Sma N 5 Kabupaten Kepulauan Tanimbar. J-EDu: Journal Erfolgreicher Deutschunterricht, $1(2$ SE-Articles). https://doi.org/10.30598/J-EDu.1.2.48-56

Salamony, L., Litualy, S., \& Kunu, G. (2021). Model Pembelajaran Pair Checks Dan Hasil Belajar Bahasa Jerman Siswa Sma Negeri 1 Ambon. J-EDu: Journal Erfolgreicher Deutschunterricht, 1(1 SE-Articles). https://doi.org/10.30598/J-EDu.1.1.24-34

Utari, T. S. G., Tresnawati, C., \& Alifah, G. N. (2021). Inovasi Pendidikan Melalui Model Pembelajaran Peer Tutoring (Tutor Sebaya) untuk Meningkatkan Hasil Belajar Siswa. Eduprof: $\quad$ Islamic $\quad$ Education $\quad J o u r n a l, ~ 3(1), \quad 14-25$. https://doi.org/https://doi.org/10.47453/eduprof.v2i2.37 